\title{
PaCha MaMa: os direitos da natureza e o nOVo CONSTITUCionalismo
} nA América Latina

Pacha mama: the rights of nature and the new constitutionalism in Latin America

\section{Marcilene Aparecida Ferreira}

Mestranda em Direito Ambiental e Desenvolvimento Sustentável - Escola Superior Dom Helder Câmara - MG, especialista em Direito Municipal pelo CEAJUFE, graduada em Direito pela PUC-MG, Procuradora-Geral do Município de Catas Altas e membro colaboradora da Comissão de Meio Ambiente da OAB/MG, e membro da Rede Nacional de Advogados Populares - RENAP.

E-mail: marcilene.catasaltas@gmail.com

RECEBIDO EM: 02.09.12

APROVADO EM: 09.01.13

Yo soy la noche, la mañana Yo soy el fuego, fuego en la oscuridad

Soy pachamama, soy tu verdad Yo soy el canto, viento de la libertad Yo soy el cielo, la inmensidad Yo soy la tierra, madre de la eternidad

Soy pachamama, soy tu verdad Yo soy el canto, viento de la libertad (SOSA, 2011) 


\section{Resumo}

O novo constitucionalismo na América Latina iniciado com as constituições do Brasil (1988), da Colômbia (1991) e da Venezuela (1999), se aflora com o plurinacionalismo comunitário, o pluralismo jurídico, os direitos da natureza e a participação popular vivenciados na experiência das Constituições do Equador (2008) e da Bolívia (2009). O presente estudo deseja provocar uma reflexão sobre os direitos da natureza, da Pacha Mama ${ }^{445}$. A natureza, com a incorporação de uma cosmovisão indígena de forma explícita na Constituição do Equador, é compreendida como sujeito de direito, situação que impõe mudanças na interpretação e na prática jurídica. Surge um movimento de luta pela liberdade da natureza, que não deve ser explorada e dominada para o uso exclusivo e sem limites pelo ser humano, situação que compromete a vida do planeta e sua própria existência. $\mathrm{O}$ artigo analisa as mudanças de um novo constitucionalismo da América Latina que se abre à solidariedade, à biodiversidade e à sociodiversidade. É tempo de reconhecer os limites da natureza e a insustentabilidade de um desenvolvimento fundado no tradicional antropocentrismo e no crescimento econômico. A humanidade deve ser colocada nos braços de Pacha Mama, se integrar a ela, para promover os direitos da natureza.

Palavras-chave: Direitos da natureza. Constitucionalismo da América Latina. Constituição do Equador.

\section{Abstract}

The new constitutionalism in Latin America, started with the constitutions of Brazil (1988), Colombia (1991) and Venezuela (1999), arises with community plurinacionalism, legal pluralism, the rights of nature and popular participation in the experience of Constitutions of Ecuador (2008) and Bolivia (2009). The present study aims to provoke a debate about the rights of nature, Pacha Mama. The nature, with the incorporation of an indigenous worldview explicitly in the Constitution of Ecuador, is understood as the subject of law, a situation that requires changes in the interpretation and legal practice. There is a movement fighting for the freedom of nature that should not be exploited and dominated for the exclusive use and unlimited by humans, jeopardizing the life of the planet and its very existence. The article analyzes the changes of a

\footnotetext{
${ }_{445}$ Pacha Mama é a mãe terra para os povos dos Andes do Peru, da Bolívia, da Argentina e do Chile.
} 
new Latin American constitutionalism that opens solidarity, biodiversity and social diversity. It is time to recognize the limits of nature and unsustainability of a development based on traditional anthropocentrism and economic growth. Humanity must be placed in the arms of Pacha Mama, integrate it, to promote the rights of nature.

Keywords: Rights of nature. Constitutionalism in Latin America. Constitution of Ecuador.

Sumário: Introdução. 1. Do novo constitucionalismo na América Latina. 2. Dos direitos da natureza. Conclusão. Referências.

\section{INTRODUÇÃO}

A ideia do presente estudo surge da provocação realizada por painelistas, durante o XX Congresso ${ }^{446}$ Nacional do Conselho Nacional de Pesquisa e PósGraduação em Direito (CONPEDI), num dos painéis que teve como tema "A proposta do neo constitucionalismo desafios e perspectivas". De forma instigante os painelistas desenvolveram as questões centrais do novo constitucionalismo, trataram do plurinacionalismo, dos movimentos sociais e indígenas envolvidos, dos direitos da natureza, e ao final provocaram os presentes para a continuidade da reflexão em seus estudos. Como bem disseram não se trata de uma teoria constitucional, mas da experiência de um novo constitucionalismo latinoamericano, a partir das experiências das Constituições do Brasil (1988), da Colômbia (1991), da Venezuela (1999), do Equador (2008) e da Bolívia (2009).

Entre as mudanças propostas pelo novo constitucionalismo na América Latina, é analisado no presente estudo, com mais ênfase, os direitos da natureza, Pacha Mama, dentro da cosmovisão indígena incorporada, que compreende a natureza como sujeito de direitos.

$\mathrm{Na}$ Comissão Pastoral da Terra é freqüente a utilização da expressão Pacha Mama, mãe terra, seja nos momentos de espiritualidade e nos depoimentos de denúncia dos conflitos ambientais, que violam os direitos humanos dos camponeses e o meio ambiente.

O presente estudo parte da análise, em especial, da Constituição do Equador(2008), considerando posicionamentos e reflexões de Alberto Acosta, presidente da Assembléia Constituinte de Montecristi.

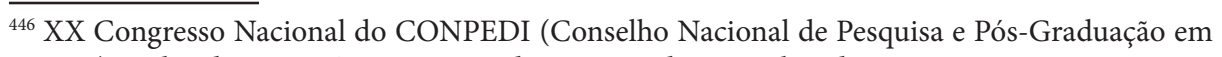
Direito), realizado em Vitória - ES, nos dias 16 a 19 de novembro de 2011. 


\section{Do novo constitucionalismo na América Latina}

A experiência do novo constitucionalismo na América Latina tem provocado a reflexão e debates entre os constitucionalistas, com destaque para as Constituições da Venezuela (1999), da Bolívia (2009) e do Equador (2008). O novo nas Constituições Andinas, impulsionadas por mudanças políticas e participação dos movimentos sociais e indígenas, aparece com perspectivas de Estado plurinacional, direitos da natureza, pluralismo jurídico, cosmovisão indígena e participação popular.

Para a professora Milena Peters, da Universitá Degli Studi Suor Orsola Benincasa, de Nápoles, Itália, citada por Elaine Tavares, essas mudanças na América Latina são influenciadas pela expansão dos direitos humanos, das garantias e direitos fundamentais e dos direitos ambientais, deflagrados na fase da transição democrática, iniciados na década de 80 e fortalecendo-se na década de 90. Percebe-se a mesma situação na Constituição Brasileira de 1988 e na Constituição da Colômbia de 1991.

É no novo milênio, como afirma Milena, que surge o "novíssimo, o original" nas constituições da América Latina e que, influenciadas pela participação popular, abrem-se à solidariedade, à biodiversidade à sociodiversidade e ao reconhecimento da cosmovisão indígena.

Mas é a partir no novo milênio que começa a fluir uma nova linfa, trazida pelas transformações políticas de caráter popular na Venezuela, Equador e Bolívia. "Essas constituições são o novíssimo, o original". Um dos elementos fundamentais dessas constituições é que elas nascem da mobilização real das gentes. São realizadas assembléias participativas, e o conceito "participação popular" torna-se real. "Essas constituições radicam-se na realidade histórica descolonizada, ligam a realidade global à local, tem um enfoque na solidariedade, atribuem valor à biodiversidade e sociodiversidade, reconhecem a cosmovisão indígena e garantem a efetiva participação popular" (TAVARES, 2011).

As novas constituições, para o professor Antônio Carlos Wolkmer (apud TAVARES, 2011), da Universidade Federal de Santa Catarina, rompem com a igualdade formal cristalizada no constitucionalismo liberal, que tem como consequência, na prática, "um estado de controle, sem democracia, com participação elitista e ausência das massas". Wolkmer (apud TAVARES, 2011) compara as "constituições da região andina" com a brasileira, ressalta os avanços em "direitos coletivos, direitos culturais, proteção aos povos indígenas e ao meio-ambiente", que é uma ruptura com a "tradição publicista liberal- 
individualista", "social-intervencionista". Afirma que a Constituição Brasileira "ainda tem muito que avançar, principalmente no que diz respeito à participação popular" (WOLKMER apud TAVARES, 2011).

No caso do Brasil, historicamente, o constitucionalismo tem sido sempre uma cópia, desde a primeira carta, em 1824, que reproduzia a Constituição francesa, incluindo aí o poder moderador. Depois, veio uma Constituição conservadora, centrada no direito dos proprietários, individualista, patriarcal, que vai até os anos 30 do século passado. A modernização impulsionada pela oligarquia desalojada do poder gera o estado corporativo, inspirado no fascismo, com controle dos sindicatos e alguns novos direitos sociais. Os anos 60, tempo da ditadura, trazem a doutrina da segurança nacional e só em 1988, sem o jugo da ditadura, a Constituição brasileira vai ampliar direitos.

A carta de 1988 não é a desejada, feita sem exclusividade e sem participação popular. Mas, ainda assim, ela avança em pontos como os direitos coletivos, direitos culturais, proteção aos povos indígenas e ao meio-ambiente (WOLKMER apud TAVARES, 2011).

$[\ldots]$

Em suma, ainda que de forma limitada e pouco satisfatória, a Carta Política de 1988 contribui para superar uma tradição publicista liberalindividualista e social-intervencionista, transformando-se num importante instrumento diretivo propulsor para um novo constitucionalismo, de tipo pluralista e multicultural (VOLKMER, 2011, pp. 151-152).

Na concepção de Raquel Yrigoyen as mudanças do constitucionalismo na América Latina se dividem em 3 fases: o constitucionalismo multicultural (1982/1988), o constitucionalismo pluricultural (1988/2005), o constitucionalismo plurinacional (2006-2009):

a) constitucionalismo multicultural (1982/1988), que introduz o conceito de diversidade cultural e reconhece direitos indígenas específicos; b) constitucionalismo pluricultural (1988/2005), que desenvolve o conceito de "nação multiétnica" e "Estado pluricultural", incorporando um largo catálogo de direitos indígenas, afro e de outros coletivos, em especial como reflexo da Convenção 169/OIT, ao mesmo tempo em que se implantam políticas neoliberais, com redução de direitos sociais e flexibilização de mercados; c) constitucionalismo plurinacional (2006- 
2009), no contexto da aprovação da Declaração das Nações Unidas sobre os direitos dos povos indígenas e que propõe a "refundação do Estado", com reconhecimento explícito das raízes milenares dos povos e discutindo o fim do colonialismo (YRIGOYEN apud BALDI, 2011).

Os constitucionalistas Raquel Yrigoyen, Bartolomé Clavero e Ramiro Ávila Santamariacompreendem na Constituição da Bolívia e do Equador uma experiência de "constitucionalismo transformador", com novos parâmetros andinos, como cita Baldi, em substituição aos "parâmetros eurocentrados do constitucionalismo":

Primeiro: a refundação do Estado é a outra face do reconhecimento tanto do colonialismo quanto das origens milenárias dos povos e nações que foram ignoradas. Uma refundação que necessita reinventar instituições e processos de organização, de que são exemplos, no caso boliviano, do Tribunal Constitucional Plurinacional, da eleição dos juízes, dos quatro níveis distintos de autonomia, e, no caso equatoriano, de "funções" (e não poderes), incluídas a de "transparência e controle social" e a "eleitoral", bem como os regimes especiais de organização territorial.

Segundo: um catálogo de direitos que rompe tanto com o geracional (civis e políticos; econômicos, sociais e culturais; terceira geração) quanto o eurocentrado. Isso fica mais evidente no caso do Equador, que reconhece sete categorias de direitos: do "buen vivir"; de pessoas e grupos de atenção prioritária (velhos, jovens, gestantes, pessoas com deficiência, privadas de liberdade, usuários e consumidores, mobilidade humana, enfermidades catastróficas); de comunidades, povos e nações; de participação; de liberdade; da natureza; de proteção; além de um apartado de responsabilidades. Mas pode ser visto no caso boliviano com a introdução de direitos das nações indígenas e um catálogo de deveres constitucionais.

Terceiro: não somente tais constituições recebem influxo da Declaração da ONU, mas fundamentalmente se constroem a partir do protagonismo indígena, de que são resultado, também, um papel diferenciado da justiça indígena (no caso boliviano, sujeita apenas do Tribunal Constitucional) e um novo léxico básico na própria cosmovisão indígena (de que o reconhecimento de direitos a "pacha mama" no Equador e dos princípiosde cunho aimará- da nação boliviana são alguns exemplos). E ressaltam a necessidade de combate ao racismo (também em relação aos povos indígenas e não somente em relação a comunidades negras, como usual). 
Quarto: a insistência tanto na descolonização (mais evidente no caso boliviano, que destaca a própria educação como descolonizadora), quanto no processo intercultural (desenvolvido de forma mais consequente no caso equatoriano). Disto se segue, também, que a "plurinacionalidade" acaba por questionar os limites do Estado constitucional e obriga uma nova institucionalidade (BALDI, 2011).

Volkmer (2011, anais p.153) divide em três ciclos esse novo consitucionalismo na América Latina, e, da mesma forma que Milena Peters, entende que o início se dá com as Constituições Brasileira (1988) e da Colômbia (1991), marcadas pelo "ciclo social e descentralizador das Constituições". O segundo ciclo é vivenciado na Constituição Venezuelana de 1997, pelas características de um "constitucionalismo participativo e pluralista". E o terceiro ciclo ocorre com as Constituições do Equador (2008) e da Bolívia (2009), marcado por um constitucionalismo plurinacional comunitário:

O terceiro ciclo do novo constitucionalismo latino-americano passa a ser representado pelas recentes e vanguardistas Constituições do Equador (2008) e da Bolívia (2009); para alguns publicistas, tais textos políticos expressariam um constitucionalismo plurinacional comunitário, identificado com um outro paradigma não universal e único de Estado de Direito, coexistente com experiências de sociedades interculturais (indígenas, comunais, urbanas e camponesas) e com práticas de pluralismo igualitário jurisdicional (convivência de instâncias legais diversas em igual hierarquia: jurisdição ordinária estatal e jurisdição indígena/camponesa) (VOLKMER, 2011, p. 153).

Nesse solo fértil, em que brota um novo constitucionalismo na América Latina, o Equador nos provoca para uma mudança de pensamento e de prática jurídica, ao inserir em seu texto Constitucional (2008) os direitos da natureza.

\section{Dos direitos da nATUREZA}

Reconhecer os direitos da natureza, compreendê-la como sujeito de direitos, na proposta da Constituição do Equador implica uma mudança de paradigma, não só para o pensamento constitucionalista, mas para todas as áreas da ciência do direito e outras ciências, desenvolvidas em bases antropocêntricas.

$\mathrm{O}$ que parece estranho para os juristas é bem compreendido pelos povos andinos, ou na cosmovisão ${ }^{447}$ indígena. A natureza deixa de ser apenas recurso

447 "Além do fato de que a Natureza faz parte ativa da cosmovisão indígena, em que os seres huma- 
natural a ser explorado e dominado pelo homem, para seu desenvolvimento em função do crescimento econômico. Alberto Acosta ${ }^{448}$, presidente da Assembléia Constituinte do Equador, diz que a construção social da conceituação do termo natureza precisa ser reinterpretada e revisada integralmente. E afirma que a humanidade é parte da natureza, que possui limite, quando colocamos a vida do planeta em risco, a vida do ser humano também está em risco.

A acumulação material - mecanicista e interminável de bens -, assumida como progresso, não tem futuro. Os limites dos estilos de vida sustentados na visão ideológica do progresso antropocêntrico são cada vez mais notáveis e preocupantes. Se quisermos que a capacidade de absorção e resiliência da terra não entrem em colapso, devemos deixar de ver os recursos naturais como uma condição para o crescimento econômico ou como simples objeto das políticas de desenvolvimento. $\mathrm{E}$, certamente, devemos aceitar que o ser humano se realiza em comunidade, com e em função de outros seres humanos, como parte integrante da Natureza, sem pretender dominá-la.

Isto nos leva a aceitar que a Natureza, como construção social, ou seja, como termo conceitualizado pelos seres humanos, deve ser reinterpretada e revisada integralmente se não quisermos colocar em risco a vida do ser humano no Planeta. Para começar qualquer reflexão aceitemos que a humanidade não está fora da Natureza e que esta tem limites (ACOSTA, 2011).

$\mathrm{Na}$ construção dos direitos da natureza transitamos do antropocentrismo ao biocentrismo, no entendimento de Gudynas, citado por Alberto, numa "transição sustentável e plural":

A vigência dos Direitos da Natureza coloca mudanças profundas. Gudynas é claro a este respeito, é preciso transitar do atual antropocentrismo ao

nos estão imersos na Natureza, a ideia de dotar de direitos a Natureza tem antecedentes inclusive no mundo ocidental. Esta tese já foi recolhida por Îtalo Calvino no século XIX, quando recordava que o barão Cosimo Piovasco de Rondò, conhecido como "o barão das árvores", durante a Revolução Francesa propôs um "projeto de Constituição para um ente estatal republicano com a Declaração dos Direitos Humanos, dos Direitos das Mulheres, das Crianças, dos Animais Domésticos e dos Animais Selvagens, incluindo pássaros, peixes e insetos, assim como plantas, quer sejam árvores ou leguminosas e ervas" (ACOSTA, 2011).

${ }^{448}$ Alberto Acosta é economista equatoriano, professor e pesquisador da FLACSO. Foi ministro de Minas e Energia do seu país entre janeiro e junho de 2007. Presidiu a Assembleia Constituinte que escreveu a nova Constituição do Equador, entre outubro de 2007 e julho de 2008. A tradução é do CEPAT. 
biocentrismo. Trânsito que exige um processo de transição sustentável e plural. A tarefa, no dizer de Roberto Guimarães, é organizar a sociedade e a economia assegurando a integridade dos processos naturais, garantindo os fluxos de energia e de materiais na biosfera, sem deixar de preservar a biodiversidade do planeta (ACOSTA, 2011).

O preâmbulo da Constituição do Equador celebra a natureza, a chama de Pacha Mama ${ }^{449}$, como os povos andinos, "reconhecimento de plurinaciocionalidade e interculturalidade", apela à sabedoria de todas as culturas e demonstra a opção por construir "uma nova forma de convivência pacífica na diversidade e harmonia com a natureza para alcançar a vida boa, sumak kawsay ${ }^{450 "}$ :

\section{Constituição da República Do Equador ${ }^{451}$ \\ Preâmbulo}

Nós, o povo soberano do Equador reconhecendo nossas raízes milenares, forjadas por mulheres e homens de diferentes povos, celebrando a natureza, Pacha Mama, da qual somos parte e que é vital para nossa existência, invocando o nome de Deus e reconhecendo nossas diversas formas de religiosidade e espiritualidade, apelando à sabedoria de todas as culturas que nos enriquecem como sociedade, como herdeiros das lutas sociais de libertação frente a todas as formas de dominação e colonialismo, e com um profundo compromisso com o presente e o futuro decidimos construir uma nova forma de convivência cidadã na diversidade e harmonia com a natureza, para alcançar o bem viver, sumak kawsay; uma sociedade que respeite, em todas as suas dimensões, a dignidade das pessoas e das coletividades; um país democrático, comprometido com a integração

\footnotetext{
449 "Igualmente transcendente foi a incorporação do termo Pacha Mama, como sinônimo de Natureza, enquanto reconhecimento de plurinacionalidade e interculturalidade" (ACOSTA, 2011). ${ }^{450}$ sumak kawsay: bem viver, na concepção dos povos indígenas andinos.

451 "Constitución de la República del Ecuador. Preámbulo. Nosotras y nosotros, el Puebla soberano del Ecuador reconociendo nuestras raíces milenarias, forjadas por mujeres y hombres de distintos pueblos, celebrando a la naturaleza, la Pacha Mama, de la que somos parte y que es vital para nuestra existencia, invocando el nombre de Dios y reconociendo nuestras diversas formas de religiosidad y espiritualidad, apelando a la sabiduría de todas las culturas que nos enriquecen como sociedad, como herederos de las luchas sociales de liberación frente a todas las formas de dominación y colonialismo, Y con un profundo compromiso con el presente y el futuro, Decidimos construir Una nueva forma de convivencia ciudadana, en diversidad y armonía com la naturaleza, para alcanzar el buen vivir, el sumak kawsay; Una sociedad que respeta, en todas sus dimensiones, la dignidad de las personas y las colectividades; Un país democrático, comprometido con la integración latino americana -sueño de Bolívar y Alfaro-, la paz y la solidaridad con todos los pueblos de la tierra; $y,[\ldots] "$ (ECUADOR, p. 15).
} 
latino-americana - sonho de Bolívar e Alfaro, a paz e a solidariedade com todos os povos da terra, e [...] (EQUADOR, 2011, tradução nossa).

Dessa construção no Capítulo sete, o Equador propõe o novo ao constitucionalizar os direitos da natureza, como ressalta Acosta (2011). A Constituição do Equador (2008) trata "a Natureza como sujeito de direitos" e soma-lhe "o direito de ser restaurada quando for destruída":

$[\ldots]$

Capítulo Sétimo ${ }^{452}$

Direitos da Natureza

Artigo 71 - Natureza ou Pachamama, onde se reproduz e realiza a vida, tem direito que se respeite integralmente a sua existência e a manutenção e regeneração de seus ciclos vitais, estrutura, funções e processos evolutivos.

452 "Capítulo séptimos

Derechos de la naturaleza

Art. 71.- La naturaleza o Pacha Mama, donde se reproduce y realiza La vida, tiene derecho a que se respete integralmente su existencia y El mantenimiento y regeneración de sus ciclos vitales, estructura, funciones y procesos evolutivos.

Toda persona, comunidad, pueblo o nacionalidad poderá exigir a La autoridad pública El cumplimiento de los derechos de La naturaleza. Para aplicar e interpretar estos derechos se observaran los princípios establecidos en La Constitución, en lo que proceda.

El Estado incentivará a las personas naturales y jurídicas, y a los colectivos, para que protejan La naturaleza, y promoverá El respeto a todos los elementos que Forman un ecosistema.

Art. 72.- La naturaleza tiene derecho a La restauración. Esta restauración será independiente de La obligación que tienen el Estado y las personas naturales o jurídicas de Indemnizar a los individuos y colectivos que dependan de los sistemas naturales afectados.

En los casos de impacto ambiental grave o permanente, incluidos los ocasionados por La explotación de los recursos naturales no renovables, el Estado establecerá los mecanismos más eficaces para alcanzar La restauración, y adoptará las medidas adecuadas para eliminar o mitigar lãs consecuencias ambientales nocivas.

Art. 73.- EI Estado aplicará medidas de precaución y restricción para lãs actividades que puedan conducir a La extinción de especies, La destrucción de ecosistemas o La alteración permanente de los ciclos naturales.

Se prohíbe La introducción de organismos y material orgánico e inorgânico que puedan alterar de manera definitiva El patrimonio genético nacional.

Art. 74.- Las personas, comunidades, pueblos y nacionalidades tendrán derecho a beneficiar se del ambiente y de las riquezas naturales que lês permitan el buenvivir.

Los servicios ambientales no serán susceptibles de apropiación; suproducción, prestación, uso y aprovechamiento serán regulados por el Estado." (ECUADOR, 2011) 
Toda pessoa, comunidade, povo ou nacionalidade poderá exigir da autoridade pública o cumprimento dos direitos da natureza. Para aplicar e interpretar esses direitos se observarão os princípios estabelecidos na Constituição, conforme o caso.

O Estado irá incentivar as pessoas físicas e jurídicas, e a coletividade, para proteger a natureza e promover o respeito a todos os elementos que formam um ecossistema.

Artigo 72 - A natureza tem o direito a restauração. Esta restauração será independente da obrigação que tem o Estado e pessoas físicas ou jurídicas em indenizar indivíduos e grupos que dependem de sistemas naturais afetados.

Em casos de impacto ambiental grave ou permanente, incluindo os relacionados com a exploração de recursos naturais não renováveis, o Estado vai estabelecer os mecanismos mais eficazes para alcançar a restauração, e adotará as medidas adequadas para eliminar ou mitigar as consequências ambientais nocivas.

Artigo 73 - EI Estado aplicará medidas de precaução e restrição de atividades que podem levar à extinção de espécies, destruição de ecossistemas ou a alteração permanente de ciclos naturais.

Proíbe-se a introdução de organismos e materiais orgânicos e inorgânicos que podem vir a alterar o patrimônio genético nacional.

Artigo 74 - As pessoas, comunidades, povos e nações têm o direito de beneficiar-se do meio ambiente e recursos naturais que lhes permitem viver bem.

Os serviços ambientais não serão suscetíveis de apropriação, sua produção, prestação, uso e aproveitamento será regulado pelo Estado (EQUADOR, 2011, tradução nossa).

Para chegar a esta concepção de natureza como sujeito de direitos a Assembleia Constituinte, em Montecristi, vivenciou muitas discussões e esforços políticos, face sua complexidade, como relata o presidente constituinte:

Vários participantes, inclusive do bloco da situação, o majoritário, assim 
como membros de alto nível do próprio governo, não quiseram aceitar os Direitos da Natureza e a acusaram inclusive de uma "estupidez". (12) Fora da Assembleia, os Direitos da Natureza foram vistos como uma "confusão conceitual" pelos conservadores do direito, essencialmente incapazes de entender as mudanças em andamento. Para eles, é difícil compreender que o mundo está em movimento permanente.

Ao longo da história legal, cada ampliação dos direitos foi anteriormente impensável. A emancipação dos escravos ou a extinção dos direitos aos afroamericanos, às mulheres e às crianças foram uma vez rechaçadas por ser considerados um absurdo. Demandou-se que ao longo da história se reconheça "o direito de ter direitos" e isto se conseguiu sempre com um esforço político para mudar aquelas leis que negavam esses direitos (ACOSTA, 2011).

Para Albert (ACOSTA, 2011) é um processo de libertação da natureza, cuja luta resgata o direito de existência da humanidade, que deve garantir a sustentabilidade e reconhecer que o capitalismo "destrói suas próprias condições biofísicas de existência":

A libertação da Natureza desta condição de sujeito sem direitos ou de simples objeto de propriedade, exigiu e exige, então, um esforço político que a reconhece como sujeito de direitos. Este aspecto é fundamental se aceitamos que todos os seres vivos têm o mesmo valor ontológico, o que não implica que todos sejam idênticos.

Dotar a Natureza de Direitos significa, então, estimular politicamente sua passagem de objeto a sujeito, como parte de um processo centenário de ampliação dos sujeitos do direito, como recordava já em 1988 Jörg Leimbacher, jurista suíço. A questão central dos Direitos da Natureza, de acordo com o mesmo Leimbacher, é resgatar o "direito à existência" dos próprios seres humanos. Este é um ponto medular dos Direitos da Natureza. Insistamos até o cansaço que o ser humano não pode viver à margem da Natureza. Portanto, garantir a sustentabilidade é indispensável para assegurar a vida do ser humano no planeta. Esta luta de libertação, enquanto esforço político, começa por reconhecer que o sistema capitalista destrói suas próprias condições biofísicas de existência (ACOSTA, 2011).

Há um movimento, inspirado nas mudanças constitucionais na América Latina, em especial na Constituição do Equador, para que seja criada uma 
Declaração Universal dos Direitos da Natureza, em âmbito do Direito Internacional, para reverter à atual crise civilizatória:

Portanto, esta definição pioneira em nível mundial, de que a Natureza é sujeito de direitos, é uma resposta de vanguarda frente à atual crise civilizatória. E como tal, foi sendo assumida em amplos segmentos da comunidade internacional, consciente de que é impossível continuar com um modelo de sociedade depredadora, baseada na luta dos seres humanos contra a acumulação de bens materiais, com as consequentes expectativas de crescimento econômico e consumo ilimitados. Neste sentido é necessário reconhecer que os instrumentos disponíveis para analisar estes assuntos já não servem. São instrumentos que naturalizam e convertem em inevitável este padrão civilizatório. São conhecimentos de matriz colonial e eurocêntrica, como acertadamente assinala o venezuelano Edgardo Lander (ACOSTA, 2011).

O $\S 3^{\circ}$. do art. 225, da Constituição (1988) do Brasil dispõe que "as condutas e atividades consideradas lesivas ao meio ambiente sujeitarão os infratores, pessoas físicas ou jurídicas, a sanções penais e administrativas, independentemente da obrigação de reparar os danos causados" (BRASIL, 2012), ou seja, possui previsão de responsabilização civil, penal e ou criminal. A jurisprudência brasileira tem aplicado esta responsabilização a partir de uma base antropocêntrica, a proteção dos direitos dos animais reconhecido em decisões judiciais abre espaço para uma reflexão jurídica sobre os direitos da natureza, para além do direito humano.

O Juiz Federal, Vladimir Santos Vitovsky, da $5^{\text {a }}$ Vara Federal de São João de Meriti, na sentença da ação civil pública ${ }^{\circ}$ 2005.51.10.005230-3, apresentada pelo ministério público federal, contra os réus Parque Ana Dantas promoções e eventos Ltda. Jonatas de Oliveira Dantas Filho, fundação estadual de engenharia do meio ambiente - FEEMA, instituto brasileiro do meio ambiente e dos recursos naturais renováveis - IBAMA, reconhece o direito do animal e usou entre os vários fundamentos o direito da natureza, citando a constituição do Equador e o art. 225 da Constituição Federal, para condenar a prática de vaquejadas ${ }^{453}$ e cita inúmeras decisões judiciais que reconhecem os direitos dos animais:

453 "[...] as atividades denominadas "vaquejadas" assim entendidas como competições cujo objetivo é derrubar o boi no local demarcado na arena por duas faixas, que estão a 10 metros uma da outra, devendo o boi cair, mostrando as quatro patas, e levantar-se dentro deste limite para "valer o boi", ou seja, disputas entre várias duplas, que montadas em seus cavalos tentam derrubar um bovino na faixa específica para a queda, com dez metros de largura, desenhadas na areia da pista com cal, na qual cada vaqueiro tem uma função, um é o batedor de esteira (encarregado de tanger o boi para perto do derrubador, e pegar o rabo do boi e passar para o colega), e o outro é o puxador (encarregado de puxar o rabo do boi e de derrubá-lo), ou similares [...]"(BRASIL, 5a․ Vara Federal de São João do Meriti, 2012). 
Maus tratos a animais de circo - Ação cautelar de busca e apreensão - Requerimento da Promotoria da Comarca de Sumaré em favor de um hipopótamo e um chimpanzé vítimas de maus tratos - Instalações inadequadas para os animais - Envio desses bichos para o Parque Ecológico Municipal de Americana (proc. n. 1445/93, $3^{\text {a }}$ Vara Cível de Sumaré).

Mortandade de peixes - Ação civil pública proposta pela Promotoria de Sorocaba contra indústria local - Redução do oxigênio da água provocada pela diminuição da vazão nas barragens de usina hidrelétrica de responsabilidade da requerida - Indenização pleiteada em vista da conseqüente mortandade de peixes do rio Sorocaba (proc. n. 2110/93, 5a Vara Cível de Sorocaba).

TV Animal - Ação civil pública ajuizada pelo Ministério Público Federal contra rede emissora de televisão que exibia imagens de maus tratos a animais, dentre as quais luta livre entre caranguejos - A requerida, abstendo-se de fazê-lo passou a veicular campanhas ecológicas - Acordo homologado - (proc. n. 89/00377540/7, da 19a Vara da Justiça Federal).

Abate cruel - Matadouro municipal que vinha abatendo gado a marretadas, método esse vedado por lei em razão do sofrimento imposto ao animal - Ação civil pública proposta na comarca de São Bento do Sapucaí Municipalidade condenada a adequar o matadouro às especificações modernas e a substituir o sistema arcaico de abate pelo método científicohumanitário (proc. n. 284/92, Comarca de São Bento do Sapucaí).

Apreensão de navio - Inquérito civil instaurado pela Promotoria de São Sebastião contra navio estrangeiro que derramou 20.000 litros de óleo nas águas litorâneas brasileiras, ocasionando sérios riscos à fauna ictiológica - Medida cautelar de Produção Antecipada de Provas para permitir imediato exame pericial na embarcação - Navio retido no porto até a prestação de caução no valor de US\$ 10 milhões, para garantir a indenização dos danos ambientais sofridos (proc. n. 429/91, Comarca de São Sebastião).

Fechamento de zoológico - Ação Civil Pública interposta pelo Ministério Público Estadual em favor de 30 animais da fauna silvestre aprisionados em condições cruéis - Estabelecimento particular montado em desconformidade à lei - Ofensa ao decreto n. 24.645/34 - pedido de 
fechamento do zôo com a reintegração dos bichos, na medida do possível, ao seu habitat natural (proc. n. 218/88, Comarca de Aparecida).

Crueldade em rodeio - Ação civil pública ajuizada pela Promotoria de Cravinhos a fim de impedir rodeio - Festa regional que envolve maus tratos e crueldade - Utilização de instrumentos e métodos que causam sofrimento aos animais - Concedida liminar para que os responsáveis pelo evento abstenham-se de usar sedém, esporas de formato pontiagudo ou cortantes e de sinos no pescoço dos animais, porque se constituem em dolorosos meios de instigação à ira do bicho (proc. n. 937/95, Comarca de Cravinhos) (BRASIL, 5a . Vara Federal de São João do Meriti, 2012).

A interpretação da Lei dos Crimes Ambientais, Lei 9605 de 1998, hoje, ainda fundada no antropocentrismo, deve se adequar as novas realidades, como afirma Azevedo. Nesse sentido a dogmática penal "a menos que se converta em instrumento ideológico destinado a dissimular ou falsear a realidade, precisa manter-se rente à vida, recebendo seu influxo e sobre ela atuando, atenta à configuração da situação humana global a que se destina", sem "perder de vista sua dimensão histórica e crítica” (AZEVEDO apud BATISTA, 2007, p. 122).

O judiciário brasileiro tem sido provocado a manifestar sobre os direitos da natureza e das gerações futuras, principalmente nos processos de licenciamento ambiental, nos conflitos ambientais territorias que surgem na apropriação por grandes empreendimentos de territórios dos povos da floresta e do campo, situação que acirram os conflitos sociais e ambientais. E como alerta a pesquisadora Andrea Zhouri (2010, p.25), “o território é entendido como patrimônio necessário para a produção e reprodução que garante a sobrevivência da comunidade como um todo".

Os direitos ambientais previstos na Declaração Universal de Direitos Humanos são insuficientes, por ter sido construída em base antropocêntrica. Alguns percebem os direitos da natureza dentro de uma visão biocêntrica, se analisado com atenção observa-se nas reflexões um caminho do meio. Eduardo Gudybas (apud ACOSTA, 2011) diferencia os direitos humanos a um ambiente saudável, visão antropocêntrica presente nas constituições, dos direitos da natureza, esses relacionados à busca "indispensável do equilíbrio entre a Natureza e as necessidades dos seres humanos".

Nos Direitos Humanos o centro está posto na pessoa. Trata-se de uma visão antropocêntrica. Nos direitos políticos e sociais, isto é, de primeira e segunda geração, o Estado reconhece aos cidadãos esses direitos, como parte de uma visão individualista e individualizadora da cidadania. Nos 
direitos econômicos, culturais e ambientais, conhecidos como direitos de terceira geração, se inclui o direito a que os seres humanos gozem de condições sociais equitativas e de um meio-ambiente saudável e não contaminado. Procura-se evitar a pobreza e a deterioração ambiental que impacta negativamente na vida das pessoas (ACOSTA, 2011).

Quando reconhecemos os Direitos da Natureza, optamos por uma visão biocêntrica centrada na natureza, considerando que a humanidade é parte dessa natureza, com todos os sistemas de vidas, como define Alberto:

A Natureza vale por si mesma, independentemente da utilidade ou dos usos que o ser humano fizer dela. É isto que representa uma visão biocêntrica. Estes direitos não defendem uma Natureza intocada, que nos leve, por exemplo, a deixar de fazer plantações, pesca ou pecuária. Estes direitos defendem a manutenção dos sistemas de vida, os conjuntos de vida. Sua atenção se fixa nos ecossistemas, nas coletividades, não nos indivíduos. Pode-se comer carne, peixes e grãos, por exemplo, enquanto se assegure que haja ecossistemas funcionando com suas espécies nativas (ACOSTA, 2011).

A Constituição do Equador ao tratar dos direitos da natureza, nos remete aos direitos ecológicos que são diferentes dos direitos ambientais, com perspectiva de uma justiça ecológica diferente da justiça ambiental:

Os Direitos da Natureza - neste caso outorgados pelo povo equatoriano, quem em última instância redigiu a Constituição através de seus constituintes e que aprovou a com uma amplíssima maioria no referendo de 28 de setembro de 2008 - são considerados direitos ecológicos para diferenciá-los dos direitos ambientais da opção anterior. Na Constituição equatoriana - diferente da boliviana - estes direitos aparecem de forma explícita como Direitos da Natureza. São direitos orientados a proteger ciclos vitais e os diversos processos evolutivos, não apenas as espécies ameaçadas e as áreas naturais.

Neste campo, a justiça ecológica pretende assegurar a persistência e a sobrevivência das espécies e seus ecossistemas, como conjuntos, como redes de vida. Esta justiça é independente da justiça ambiental. Não é de sua incumbência a indenização aos humanos pelo dano ambiental. Expressa-se na restauração dos ecossistemas afetados. $\mathrm{Na}$ realidade, devem-se aplicar simultaneamente as duas justiças: a ambiental para as pessoas, e a ecológica para a Natureza (ACOSTA, 2011). 
Na jurisprudência do Equador, em 30 de março de 2011, em sentença que julgou o recurso judicial $N^{o}$ 11121-2011-001, interposto por Richard Fredrick Wheeler e Eleanor Geer Huddle, o juiz Luiz Sempértegui Valdivieso, da Corte Provincial da Justiça de Loja - Sala Penal, decidiu em favor dos direitos da natureza.

[...] Por estas considerações, administrando justiça em nome dos povos do Equador, e por autoridade da constituição e das leis da República, esta sala resolve: 1) Aceitar o recurso interposto e revogar a sentença impugnada declarando que a entidade demandada está violando o direito que a Natureza tem de que se respeite integralmente sua existência e a manutenção e regeneração de seus ciclos vitais, estrutura, funções e processos evolutivos; [...] (EQUADOR, 2012, tradução nossa) $)^{454}$.

Desafia-se a fazer uma releitura do art. 225, da Constituição Federal (1988), a partir de uma análise que permita aplicar a justiça ecológica, a natureza deixa de estar exclusivamente em função dos humanos, nos tornamos parte dessa natureza. E considerando a atual sociedade de risco, na perspectiva do magistrado, Zenildo Bodnar (2009), "a jurisdição deverá contribuir decisivamente com a consolidação de novos modelos de gestão, governança e regulação", e direcionado a uma sustentabilidade com inclusão social, prudência ambiental e respeito aos direitos fundamentais das gerações presentes e futuras.

\section{Capítulo VI}

Do meio ambiente

Art. 225. Todos têm direito ao meio ambiente ecologicamente equilibrado, bem de uso comum do povo e essencial à sadia qualidade de vida, impondo-se ao Poder Público e à coletividade o dever de defendê-lo e preservá- lo para as presentes e futuras gerações.

$\S 1^{\circ}$ - Para assegurar a efetividade desse direito, incumbe ao Poder Público:

I - preservar e restaurar os processos ecológicos essenciais e prover o manejo ecológico das espécies e ecossistemas;

II - preservar a diversidade e a integridade do patrimônio genético do País e fiscalizar as entidades dedicadas à pesquisa e manipulação de material genético;

\footnotetext{
454 "[...] Por estas consideraciones, administrando justicia en nombre del pueblos del Ecuador, y por autoridad de la constitucion y las leyes de la República, esta sala resuelve: 1) Aceptar el recurso planteado y revocar la sentencia impugnada declarando que la entidade demandada está violentando el derecho que la Naturaleza tiene de que se le respete integralmente su existência y el mantenimiento y regenración de sus ciclos vitales, estructura, funciones y processos evolutivos; [...]"
} 
III - definir, em todas as unidades da Federação, espaços territoriais e seus componentes a serem especialmente protegidos, sendo a alteração e a supressão permitidas somente através de lei, vedada qualquer utilização que comprometa a integridade dos atributos que justifiquem sua proteção; IV - exigir, na forma da lei, para instalação de obra ou atividade potencialmente causadora de significativa degradação do meio ambiente, estudo prévio de impacto ambiental, a que se dará publicidade;

V - controlar a produção, a comercialização e o emprego de técnicas, métodos e substâncias que comportem risco para a vida, a qualidade de vida e o meio ambiente;

VI - promover a educação ambiental em todos os níveis de ensino e a conscientização pública para a preservação do meio ambiente;

VII - proteger a fauna e a flora, vedadas, na forma da lei, as práticas que coloquem em risco sua função ecológica, provoquem a extinção de espécies ou submetam os animais a crueldade (BRASIL, 2012).

Trata-se aqui de um direito de todos ao meio ambiente ecologicamente equilibrado na concepção abordada por Paulo Affonso Leme Machado (2008, pp. 204-205) o direito de cada pessoa e transindividual, de um direito que se espraia para uma coletividade indeterminada, inserido no contexto dos novos direitos. Os direitos da natureza, além de aparecer como tema atual de seminários e congressos, dos grupos de pesquisas com constitucionalistas que contribuem na construção da doutrina, já influenciam a fundamentação dos processos ambientais. No Brasil, a defesa dos direitos da natureza foi apresentada pela primeira vez ao judiciário, na Ação Civil Pública, interposta pelo Ministério Público Federal do Pará (MPF/PA), no dia 17 de agosto de 2011, com pedido de paralisação das obras da hidrelétrica de Belo Monte, no rio Xingu.

"Belo Monte encerra vários confrontos: entre a geração de energia hidrelétrica e os direitos indígenas; entre o interesse de empreiteiras e o direito da natureza; entre o direito ao crescimento econômico e os princípios do direito ambiental", dizem na ação os procuradores da República Felício Pontes Jr, Ubiratan Cazetta, Bruno Valente, Daniel Avelino, Bruno Gütschow e Cláudio Terre do Amaral.

Se posicionando nesse confronto, os procuradores que acompanham o empreendimento apresentam como argumento à Justiça, pela primeira vez, o direito da natureza, violado por Belo Monte. A usina, de acordo com todos os documentos técnicos produzidos, seja pelo IBAMA, pelas empreiteiras responsáveis pelos estudos, seja pela FUNAI, o MPF ou os 
cientistas que se debruçaram sobre o projeto, vai causar a morte de parte considerável da biodiversidade na região da Volta Grande do Xingu trecho de $100 \mathrm{~km}$ do rio que terá a vazão drasticamente reduzida para alimentar as turbinas da hidrelétrica.

Esse trecho do Xingu é considerado, por decreto do Ministério do Meio Ambiente (Portaria MMA n 9/2007), como de importância biológica extremamente alta, pela presença de populações animais que só existem nessa área, essenciais para a segurança alimentar e para a economia dos povos da região. A vazão reduzida vai provocar diminuição de lençóis freáticos, extinção de espécies de peixes, aves e quelônios, a provável destruição da floresta aluvial e a explosão do número de insetos vetores de doenças (PARÁa, 2011).

$\mathrm{Na}$ Ação Civil Pública, cientes da estranheza que podem causar ao judiciário, ou da rejeição comum ao novo, representado pela tese que trata dos direitos da natureza, logo o MPF/PARÁ adverte:

"Quando os primeiros abolicionistas brasileiros proclamaram os escravos como sujeitos de direitos foram ridicularizados. No mesmo sentido foram os defensores do sufrágio universal, já no século XX. Em ambos os casos, a sociedade obteve incalculáveis ganhos. Neste século, a humanidade caminha para o reconhecimento da natureza como sujeito de direitos. A visão antropocêntrica utilitária está superada. Significa que os humanos não podem mais submeter a natureza à exploração ilimitada", diz a ação judicial (PARÁa, 2011).

$[\ldots]$

A aplicação do direito da natureza não se coaduna com a destruição do ecossistema Volta Grande do Xingu, levando a extinções de espécies já ameaçadas ou endêmicas. Nada disso deve parecer estranho ao profissional do Direto no Brasil. A legislação pátria já vem decretando o fim do antropocentrismo utilitário de ha muito. Prova disso é o art. 225, §1o, VII, da Carta de 1988 dispõe expressamente sobre o dever do Estado e da coletividade em proteger a fauna e a flora ("para assegurar a efetividade desse direito incumbe ao Poder Publico: proteger a fauna e a flora, vedadas, na forma da lei, as práticas que coloquem em risco sua função ecológica, provoquem a extinção das espécies ou submetam os animais a crueldade"). A Lei no 6.938, de 31 de agosto de 1981 (Política Nacional do Meio 
Ambiente) considera "meio ambiente, o conjunto de condições, leis, influencias e interações de ordem física, química e biológica, que permite, abriga e rege a vida em todas as suas formas" (art. 3o, inc. I) e também impedidora do AHE Belo Monte(PARÁb, 2011).

Na compreensão do MPF/Pará, os direitos da natureza é uma imposição necessária de limitações ecológicas à ação humana, com mudança da doutrina antropocêntrica utilitária para o antropocentrismo alargado ou moderado, pois a natureza possui valores intrínsecos, por si mesmo, e assim não podem ser "mensurados de acordo com sua utilidade para as aspirações humanas":

A nova doutrina surge da ameaça causada pela exploração irracional da natureza. Todos os povos e espécies vivas já sentem as conseqüências ambientais dessa exploração. A doutrina antropocêntrica utilitária colocou em risco a própria humanidade. E necessário impor limitações ecológicas a ação humana.

Faz-se isso através da compreensão de que a natureza possui valor intrínseco, não apenas instrumental. Passa-se da doutrina antropocêntrica utilitária para o antropocentrismo alargado ou moderado. Trata-se da conciliação entre os direitos humanos e os direitos da natureza:

Assim, a natureza perde seu caráter instrumental, todos os seres vivos possuem valor próprio, que não podem ser mesurados de acordo com sua utilidade para as aspirações humanas. Da mesma forma, a biodiversidade também deve ser valorada por ela mesma, e não apenas por contribuir para o bem-estar humano (PARÁb, 2011).

Nossa realidade necessita de um pensar ético e solidário, “[...] a solidariedade que o direito proclama exige uma mudança de comportamento, um olhar e agir ético perante o outro. Considerando que somos animais integrantes da natureza, o homem não pode deixar de pautar seus atos em uma ética ambiental e social” (SILVA, 2011, pp. 140-141).

O desafio está posto. A concretização dos direitos da Natureza aprovada na Constituição do Equador e proposta para o âmbito mundial requer enfrentamento aos interesses do poderio econômico nacional e transnacional:

Apesar dos avanços constitucionais obtidos, desde a entrada em vigor da nova Constituição equatoriana, em outubro de 2008, se transitou por uma vereda complicada no que se refere à aplicação de suas normas, 
patrocinadas pelo Executivo, que contradizem princípios constitucionais no campo dos direitos ambientais e da Natureza especialmente. Portanto, conscientes de que não será fácil cristalizar estas transformações no Equador, sabemos que sua aprovação será ainda muito mais complexa em nível mundial. Sobretudo na medida em que estas afetam os privilégios dos círculos de poder nacionais e transnacionais, que farão o impossível para deter este processo de libertação. Mais, a partir da vigência dos Direitos da Natureza é indispensável vislumbrar uma civilização pós-capitalista.

Tendo um marco referencial constitucional transformador como o de Montecristi a tarefa consiste em enfrentar democraticamente a luta pela vida, que é o que está realmente em jogo. E, certamente, será necessário colocar em prática uma estratégia internacional para poder potencializar tantos princípios de vanguarda que a Constituição equatoriana tem, como poderia ser impulsionar a Declaração Universal dos Direitos da Natureza. (ACOSTA, 2011)

Requer do pensamento jurídico uma busca pela sustentabilidade, capaz de concretizar de forma solidária, conforme Juarez de Freitas, "um desenvolvimento material e imaterial, socialmente inclusivo, durável e equânime, ambientalmente limpo, inovador, ético e eficiente", que visa "consonância homeostática ${ }^{455} \mathrm{com}$ o bem de todos" (FREITAS, 2011, p. 40).

\section{Conclusão}

Ao refletir sobre as mudanças ocorridas nas constituições da América Latina, depois de percorrer os avanços dos textos das constituições do Brasil(1988), da Colômbia(1991), da Venezuela (1999), do Equador (2008) e da Bolívia (2009), percebe-se que o novo constitucionalismo se aflora com mudanças paradigmáticas nas duas últimas.

As constituições do Equador e da Bolívia incorporam a força de resistência dos povos andinos, com sua cosmovisão indígena, as concepções plurinacional comunitárias, o pluralismo jurídico, os direitos da natureza e a participação popular. Esse novo constitucionalismo da América Latina se abre à solidariedade, à biodiversidade e à sociodiversidade.

É tempo de reconhecer os limites da natureza e a insustentabilidade de

\footnotetext{
${ }^{455}$ Homeostática - refere-se a "homeostase como ação deliberada de reequelíbrio dinâmico a favor da vida, sem deixar de fazer as intervenções necessárias. Não faz sentido, por exemplo, conservar nada que possa ser destrutivo para a saúde humana, sob pena de conservacionismo simplista" (FREITAS, 2011, pp. 50-51).
} 
um desenvolvimento fundado no antropocentrismo radical e no crescimento econômico.a qualquer custo. A humanidade deve ser colocada nos braços de Pacha Mama, se integrar a ela, para promover os direitos da natureza. Os movimentos sociais e os povos indígenas são atores centrais na luta pela liberdade da natureza.

As mobilizações e lutas sociais serão necessárias para a mudança de interpretação e da prática jurídica, que deverá se abrir para a compreensão da natureza como sujeito de direitos. Precisamos, nós atores da ciência do direito, mirar nas lutas dos movimentos sociais e povos indígenas, que denunciam a face violenta dos interesses do poder do capital, expressos nos grandes empreendimentos transnacionais, para escutar o grito de Pacha Mama. A luta pela liberdade da natureza e pelo bem viver é uma luta por justiça ambiental e social, para a qual todos são convocados. 


\section{REFERÊNCIAS}

ACOSTA, Alberto. Por uma Declaração Universal dos Direitos da Natureza. Reflexões para a ação. Revista Cidadania a Meio Ambiente. São Francisco de Quito, AFESE (Serviço Exterior Equatoriano), n. 54, agosto 2010. Disponível em: http://www.ecodebate.com.br/2011/03/31 /por-uma-declaracao-universaldos-direitos-da-natureza-reflexoes-para-a-acao-artigo-de-alberto-acosta/. Acessado em: 01.10.2011.

BALDI, César Augusto. Novo constitucionalismo latino-americano. Jornal Estado de Direito. 32 ed. Disponível em: http://www.estadodedireito.com. br/2011/11/08/novo-constitucionalismo-latino-americano/. Acessado em: 28.11.2011.

BATISTA, Nilo. Introdução crítica ao direito penal brasileiro. 11. ed. Rio de Janeiro: Revan, 2007.

BODNAR, Zenildo. Os novos desafios da jurisição para a sustentabilidade na atual sociedade de risco. Veredas do Direito, vol.6 - julhoddezembro de 2009. Belo Horizonte: Escola Superior Dom Helder Câmara, 2009.

BRASIL, 5 $5^{\text {a }}$ Vara Federal de São João de Meriti. Sentença $-A C P n^{\circ}$ 2005.51.10.005230-3. Disponível em: http://jurisprudenciabrasil.blogspot. com.br/ 2009/09/jurid-vara-do-rj-proibe-vaquejadas.html. Acessado em: 16.10.2012.

BRASIL. Constituição da República Federativa do Brasil de 1988. Disponível em: http://www.planalto.gov.br/ccivil_03/constituicao/constitui\%C3\%A7ao. htm. Acessado em: 05.05.2012.

ECUADOR. Constitucion 2008 La República Del Ecuador. Disponível em: http://www.asambleanacional.gov.ec/documentos/constitucion_de_bolsillo. pdf. Acessado em: 25.11. 2011.

EQUADOR, Corte Provincial da Justiça de Loja. Sentença em Recurso Judicial $N^{o}$ 11121-2011-001. Disponível em: http://ivopoletto.blogspot.com.br/2011/09/ no-equador-condenacao-por-ferir.html. Acessado em 12.06.2012.

FREITAS, Juarez. Sustentabilidade: direito ao futuro. Belo Horizonte: Fórum, 2011. 
MACHADO, Paulo Affonso Leme Machado. O Direito ao meio ambiente, os espaços protegidos e intergição da crueldade contra animais na jurisprudência do STF. I Congresso Brasileiro da Advocacia Ambiental: OABMA - São LuisMA. Coord. MURAD, Samir Jorge, ACETI JÚNIOR, Luiz Carlos, GRAU NETO, Werner. São Paulo: Fiuza, 2008.

PARÁ, Procuradoria da República, Ministério Público Federal. Ação civil pública ambiental com pedido de liminar em face de Norte Energia S/A (NESA), concessionária de Uso de Bem Publico para exploração da UHE Belo Monte. Belém, 17 agosto de 2011. Disponível em: http:/www.prpa.mpf.gov.br /news/2011/BeloMonte_Remocao.pdf. Acessado em: 11.11.2011.

PARÁ, Procuradoria da República, Ministério Público Federal. MPF/PA pede paralisação das obras de Belo Monte para evitar remoção de índios. Disponível em: http://www.prpa.mpf.gov.br/news/2011/mpf-pede-paralisacao-das-obrasde-belo-monte-para-evitar-remocao-de-indios. Acessado em: 26.11.2011.

TAVARES, Elaine. América Latina é o berço do novo. Agência de Informação Frei Tito para a América Latina. Disponível em: http://www.adital.com.br/ hotsite_ecumenismo/noticia_imp.asp?cod=60450\&lang=PT. Acessado em: 28.11.2011.

SILVA, Marcela Vitoriano e. O princípio da solidariedade intergeracional: um olhar do direito para o futuro. In: Veredas do Direito: Direito Ambiental e Desenvolvimento Sustentável. vol. 8, n. 16. Belo Horizonte: Escola Superior Dom Helder Câmara, 2011.

SOSA, Mercedes. Vientos del alma. Disponível em: http:/www.radio. uol.com. $\mathrm{br} / \# /$ letras-e-musicas/mercedes-sosa/vientos-del-alma/1073019. Acessado em: 09.12.2011.

VOLKMER, Antônio Carlos. Pluralismo e crítica do constitucionalismo na América Latina. In: Anais do IX Simpósio de Direito Constitucional da ABDConst. Curitiba, ABDConst., 2011. Disponível em: http://www.abdconst. com.br/revista3/ anaiscompletos.pdf. Acessado em: 30.11.2011.

ZHOURI, Andréa. Desenvolvimento e conflitos ambientais: um novo campo de investigação. In: ZHOURI, Andréa; LANCHEFSKI, Klemens (Org.). Desenvolvimento e Conflitos Ambientais. Belo Horizonte: UFMG, 2010. 